\title{
Retraction note: Microstructure and Strength of B2-ordered (Ni,Co)Al
}

\section{Chang Suk Han}

\section{Retraction note: Met. Mater. Int., Vol. 14, No. 3, pp. 291-295 (2008) \\ DOI: 10.3365/met.mat.2008.06.291}

This Retraction Note expands on the Retraction Note previously published in Metals and Materials International, November 2014, Volume 20, Issue 6, p 1169 (http://dx.doi.org/10.1007/s12540-014-6024-4)

The editorial board of Metals and Materials International has decided to retract this article for reasons of plagiarism.

Several paragraphs and figures in the manuscript have been used without indication that those paragraphs and figures had been published previously. The most original source papers are:

Crystal structure and morphology of Co precipitates in B2-ordered (Ni,Co) Al

W. H. Tian, M. Hibino and M. Nemoto, Intermetallics 6 (1998) 121-129

Phase decomposition and hardening of Ag-modified $\mathrm{LI}_{2}-\mathrm{Al} \mathrm{I}_{3} \mathrm{Ti}$

W. H. Tian and M. Nemoto, Intermetallics 6 (1998) 193-200

The online version of the original article can be found under doi: 10.3365/met.mat.2008.06.291

\section{Chang-Suk Han*}

Dept. of Defense Science \& Technology, Hoseo University

165, Sechul-ri, Baebang-myeon, Asan-si, Chungnam 336-795, Korea e-mail: hancs@hoseo.edu CKIM and Springer 